\title{
Capillary Electrophoresis with Chemiluminescent Detection for Luminol Using Potassium Ferricyanide as a Catalyst
}

\author{
Kazuhiko TsukagoshI, ${ }^{\dagger}$ Yukiteru OuJI, and Riichiro NaKaJIMA \\ Department of Chemical Engineering and Materials Science, Faculty of Engineering, Doshisha University, \\ Kyotanabe, Kyoto 610-0321, Japan
}

(Received March 14, 2001; Accepted May 21, 2001)

\begin{abstract}
Absorption and fluorescence detectors have been most commonly used for capillary electrophoresis (CE), which is performed with on-capillary detection. On the other hand, several groups have studied $\mathrm{CE}$ with a chemiluminescence (CL) detector. ${ }^{1-4}$ This system can offer excellent analytical selectivity and sensitivity. ${ }^{5}$ We have applied several CL reagents to $\mathrm{CE}$ with a CL detector, such as luminol, ${ }^{6}$ peroxyoxalate, ${ }^{3,7}$ and $\mathrm{Ru}(\mathrm{II})$ complex. $^{8}$ Luminol and isoluminol isothiocyanatelabeled compounds were analyzed using CE with a CL detector and microperoxidase as a catalyst. ${ }^{6}$ However, microperoxidase is expensive, and sometimes has problems in a capillary due to its large molecular size.

In this study, we examined the electrophoretic behavior of ferricyanide ion in a capillary by use of a batch-type detection cell. On the basis of the obtained information, we proposed and developed CE with a CL detector using potassium ferricyanide, instead of microperoxidase, as a catalyst for determining luminol or its derivative. A repeated injection analysis of luminol was achieved by using a flow-type CL detection cell.
\end{abstract}

\section{Experimental}

All of the reagents used were of commercially available special grade. Ion-exchanged water was distilled for use. Luminol, potassium ferricyanide, and $\mathrm{H}_{2} \mathrm{O}_{2}$ were purchased from Nacalai Tesque, Inc.

An apparatus of $\mathrm{CE}$ with a $\mathrm{CL}$ detector was made while referring to previous work. ${ }^{6-8}$ A high voltage $(12 \mathrm{kV})$ was applied to electrodes using a DC power supply (Model HCZE30PNO.25, Matsusada Precision Devices Co. Ltd.). A fusedsilica capillary of $50 \mathrm{~cm}$ length and $75 \mu \mathrm{m}$ i.d. (GL Sciences Inc.) was used. Luminol was used as a model sample. The sample was dissolved in a $10 \mathrm{mM}$ phosphate buffer ( $\mathrm{pH} 10.8$ ), which was used as a migration buffer. Sample injections were performed by siphoning from a height of $20 \mathrm{~cm}$ for $10 \mathrm{~s}$. The sample of luminol was migrated toward the CL detection cell, batch- or flow-type, and then mixed with the reagent. The resulting $\mathrm{CL}$ at the capillary outlet was captured by a photomultiplier tube (PM) equipped in a CL detector (Model EN-21, Kimoto Electric, Inc.).

The concept of a batch-type CL detection cell was originally proposed by us in a previous paper. ${ }^{6}$ The detection cell was made of Teflon, which had a $4 \mathrm{~cm}$ outer diameter, $2.5 \mathrm{~cm}$

† To whom correspondence should be addressed. height, and an $8 \mathrm{ml}$ inner volume. An optical fiber (core diameter of $2 \mathrm{~mm}$ ), a capillary, and a platinum wire as a grounding electrode were fixed to the cell. That is, the detection cell also served as an outlet reservoir. The optical fiber was set up straight to the capillary with a distance of 0.3 $\mathrm{mm}$ between them. When the sample emerged from the capillary, it reacted with the reagent at the capillary outlet to produce visible light. In the batch-type cell, potassium ferricyanide $(25 \mathrm{mM})$ as a catalyst and $\mathrm{H}_{2} \mathrm{O}_{2}(10 \mathrm{mM})$ were added to the inlet and outlet reservoirs, respectively. Usage A: the catalyst was added to the inlet reservoir and $\mathrm{H}_{2} \mathrm{O}_{2}$ was added to the outlet reservoir or the $\mathrm{CL}$ detection cell, and in reverse Usage $\mathrm{B}: \mathrm{H}_{2} \mathrm{O}_{2}$ was added to the inlet reservoir, and the catalyst to the outlet reservoir.

A schematic diagrams of the CE system with the flow-type $\mathrm{CL}$ detection cell is shown in Fig. 1. The phosphate buffer $(\mathrm{pH}$ 10.8) containing $25 \mathrm{mM}$ potassium ferricyanide was fed through a Teflon-tube by siphoning at $15 \mathrm{~cm}$ height. A sample of luminol was migrated in a migration buffer containing $10 \mathrm{mM}$ $\mathrm{H}_{2} \mathrm{O}_{2}$ to the CL detection cell, and was then mixed with the catalyst at the tip of the capillary to produce visible light. The light was directly captured by a PM without an optical fiber.

\section{Results and Discussion}

Much information concerning reagent concentration, mixing order, mixing method, etc. has been reported for CL detection in conjunction with FIA and HPLC for establishing a highly sensitive and reproducible system. However, there seems to have been a paucity of information about CL detection in CE, until now. Luminol CL generally requires that luminol or its derivatives be mixed with $\mathrm{H}_{2} \mathrm{O}_{2}$ and a catalyst. If the three components are not introduced as separate streams, the peroxide is destroyed by the catalyst before reacting with luminol or its derivatives, and no CL is observed. In order to provide useful information on connecting the CE system with the CL detector, the way to mix $\mathrm{H}_{2} \mathrm{O}_{2}$ and the catalyst was examined by the two usage procedures (Usages $\mathrm{A}$ and $\mathrm{B}$ ) described above, using batch-type CL detection.

No CL signal was observed when potassium ferricyanide was added to the inlet reservoir (Usage A). In the present system, the velocities (toward the capillary outlet) of electroosmotic flow and migration of ferricyanide ion were estimated to be $c a$. +0.13 and $-0.32 \mathrm{~cm} \mathrm{~s}^{-1}$, respectively. Therefore, the anion could not be introduced into the $\mathrm{CL}$ detection cell from the 


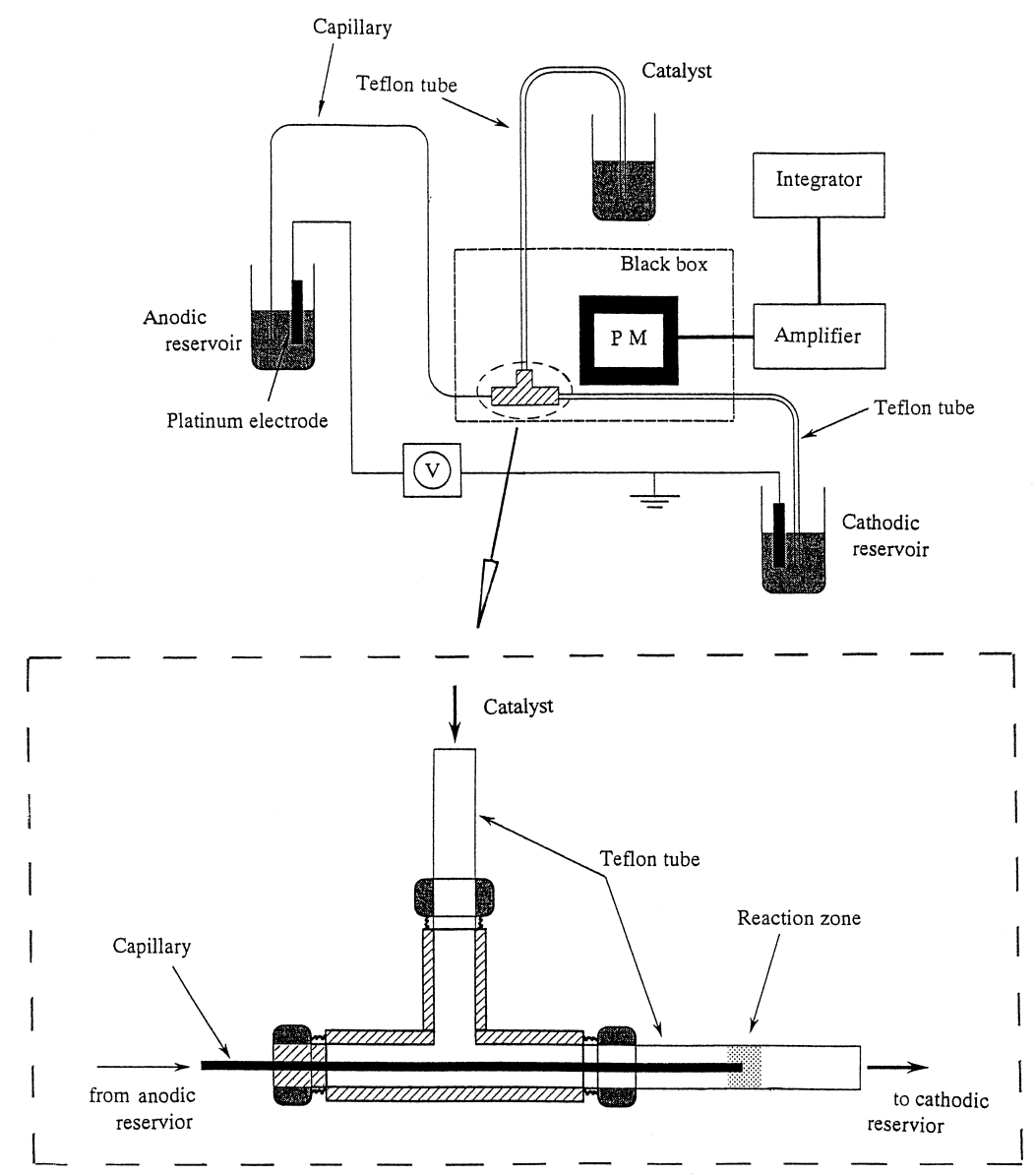

Fig. 1 Schematic diagram of the CE with a CL detector using a flow-type CL detection cell.

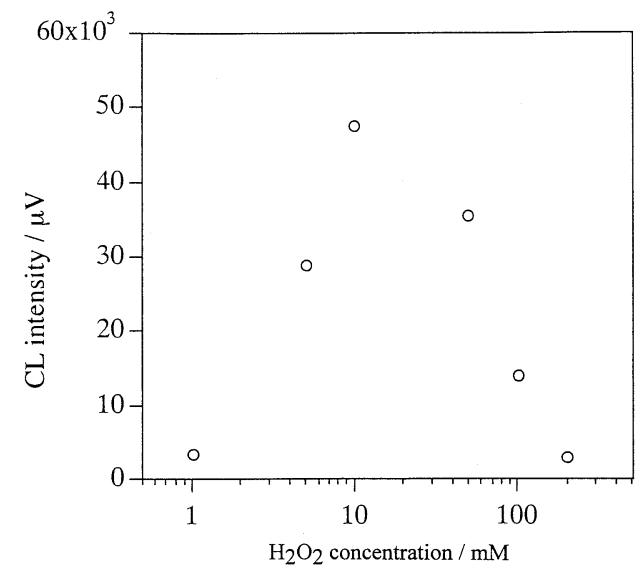

Fig. 2 Effect of the $\mathrm{H}_{2} \mathrm{O}_{2}$ concentration on the $\mathrm{CL}$ intensity of luminol. Conditions: capillary, $50 \mathrm{~cm}$ length of $75 \mu \mathrm{m}$ i.d.; applied voltage, $12 \mathrm{kV}$; migration buffer, $10 \mathrm{mM}$ phosphate buffer $(\mathrm{pH} 10.8)$ containing $\mathrm{H}_{2} \mathrm{O}_{2}$; catalyst, $25 \mathrm{mM}$ potassium ferricyanide; and sample, $1 \times 10^{-7} \mathrm{M}$ luminol.

capillary, which might result in the absence of CL. In Usage B, when potassium ferricyanide was added to the outlet reservoir, luminol showed a relatively high sensitivity. However, the CL signal decreased markedly in repeated injection analysis, and finally disappeared. The ferricyanide ion must migrate from the outlet reservoir to the inlet reservoir. The electrophoretic behavior of the anion led to a decreasing CL signal of luminol in repeated injection analysis. Luminol and $\mathrm{H}_{2} \mathrm{O}_{2}$ in the migration buffer reacted with ferricyanide ion in the capillary, which migrated from the outlet reservoir. Visible light appeared in the capillary, and then the light became less intense when the sample zone of luminol reached the capillary outlet in the batchtype cell.

The flow-type CL detection cell could improve the defect of the decreasing CL signal. Luminol migrated in the migration buffer containing $\mathrm{H}_{2} \mathrm{O}_{2}$ always reacted with fresh potassium ferricyanide at the tip of capillary which was delivered through Teflon-tube by siphoning. The distance between the end of capillary and the electrode was $c a .8 \mathrm{~cm}$. There was no problem concerning the distance for electrophoresis because of the buffer containing sufficient electrolytes. The effect of the $\mathrm{H}_{2} \mathrm{O}_{2}$ concentration on the CL intensity was examined (Fig. 2). The maximum CL intensity was observed at around $10 \mathrm{mM} \mathrm{H}_{2} \mathrm{O}_{2}$, and the concentration was used for this study. The effect of the potassium ferricyanide concentration on the CL intensity was also examined (the data not shown), and a concentration of 25 $\mathrm{mM}$ was recommended. Figure 3 shows the relationship between the height of the vessel containing the potassium ferricyanide solution and the CL intensity. It was found that the height or the flow-rate influenced the CL intensity; and a height of $15 \mathrm{~cm}$ was used in this study.

The electropherogram of luminol was examined under the optimized analytical conditions; the obtained result is shown in Fig. 4. A repeated injection analysis of luminol was achieved by use of a flow-type CL detection cell. The relative standard deviation of $1 \times 10^{-7} \mathrm{M}$ luminol was within $3 \%(n=10)$. We examined the calibration curve of luminol; the determinable 


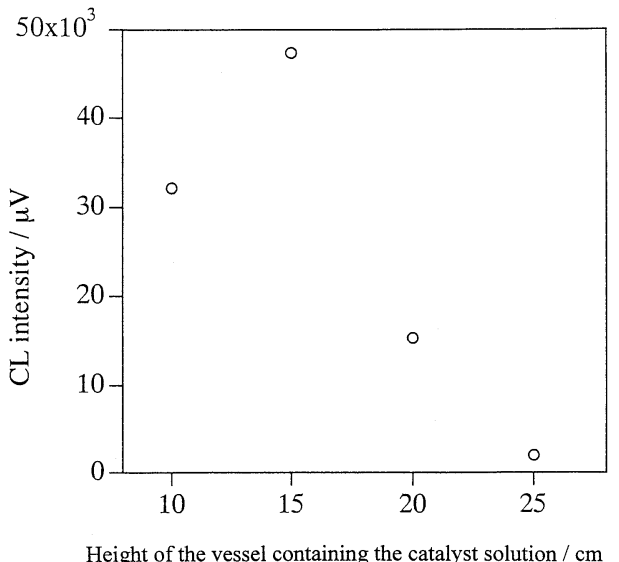

Fig. 3 Relationship between the height of the vessel containing potassium ferricyanide solution and the CL intensity of luminol. The experiments were carried out under the conditions described in Fig. 2, except for $10 \mathrm{mM} \mathrm{H}_{2} \mathrm{O}_{2}$.

range of luminol was $8.0 \times 10^{-9}-1.0 \times 10^{-6} \mathrm{M}$ (correlation coefficient, 0.999). Daddo and co-workers reported an excellent design for $\mathrm{CE}$ with $\mathrm{CL}$ detection, and derived the detection limit of luminol to be $2.0 \times 10^{-8} \mathrm{M}^{4}$ The present system seems to become one of the most promising ways in $\mathrm{CE}$ with a CL detector.

\section{Acknowledgements}

This work was supported by a grant to RCAST at Doshisha University from the Ministry of Education, Japan. This was also supported in part by Doshisha University's Research Promotion Fund.

\section{References}

1. G. A. Forbes, T. N. Nieman, and J. V. Sweedler, Anal. Chim. Acta, 1997, 347, 289.

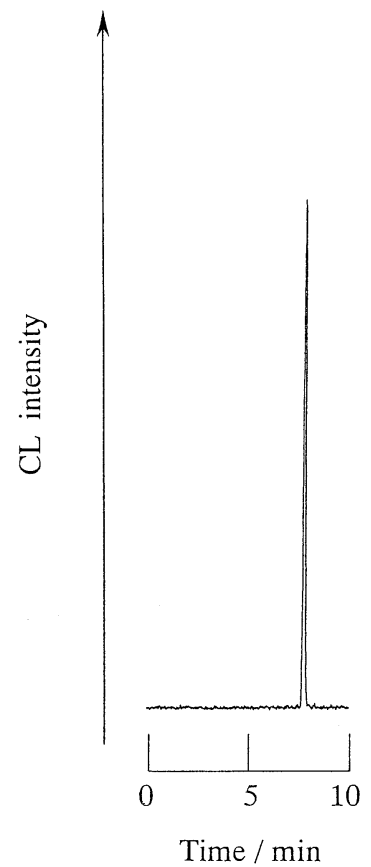

Fig. 4 Elecropherogram of luminol. The experiments were carried out under the conditions described in Fig. 3.

2. B. Huang, J. J. Li, L. Zhang, and J. K. Cheng, Anal. Chem., 1996, 68, 2366.

3. K. Tsukagoshi, A. Tanaka, R. Nakajima, and T. Hara, Anal. Sci., 1996, 12, 525.

4. R. Daddo, L. A. Colon, and R. N. Zare, Anal. Chem., 1994, 66, 303

5. A. M. G. Campana, W. R. G. Baeyens, and Y. N. Zhao, Anal. Chem., 1997, 69, A83.

6. M. Hashimoto, K. Tsukagoshi, R. Nakajima, and K. Kondo, J. Chromatogr. A, 1999, 832, 191.

7. K. Tsukagoshi, Y. Okumura, and R. Nakajima, J. Chromatogr. A, 1998, 813, 402.

8. K. Tsukagoshi, K. Miyamoto, E. Saiko, R. Nakajima, T. Hara, and K. Fujinaga, Anal. Sci., 1997, 13, 639. 